\title{
Temperature changes of Seebeck coefficient of SbSJ modified
}

\author{
B.Garbarz \\ Institute of Physics and Computer Science, Pedagogical University, \\ 2 Podchorążych Str., 30-084 Kraków, Poland
}

Received September 1, 1998, in final form October 30, 1999

The temperature dependency of Seebeck coefficient has been measured for a needle-shaped crystal of SbSJ: $0.1 \% \mathrm{Cl}$. The measurements have been made in the temperature range from $190 \mathrm{~K}$ to $370 \mathrm{~K}$. The obtained results made it possible to determine the type and the mechanisms of electric conduction.

Key words: SbSJ, Seebeck coefficient

PACS: 72.20.-i, 77.84.-s, 72.80.-r

\section{Introduction}

A remarkably interesting coexistence of ferroelectric and semiconducting properties and the possibility of their practical application causes a great interest in investigating the semiconducting ferroelectric materials. They form a separate class of non-linear ferroelectrics, in which several new phenomena and properties can be observed, and in which most processes reveal specific singularities in the phase transition points. However, a great variety of structural defects, an indeterminate band structure, a complicated dependence of current components, and so on, make them inconvenient for investigations. Among the materials revealing the ferroelectric phase transitions and, at the same time, the semiconducting properties, a special group is formed by the complexes of $\mathrm{A}^{5} \mathrm{~B}^{6} \mathrm{C}^{7}$-type. To this group belongs the antimony sulphide iodide SbSJ.

Pure SbSJ has been investigated by various workers over the years [1-5]. Because of too little information about the electric properties of SbSJ:0.01\% Cl, the author of this paper has undertaken the investigations of temperature changes of Seebeck coefficient of this material.

The measurements were performed in the temperature range from $190 \mathrm{~K}$ to $370 \mathrm{~K}$ (this covers the ranges, where ferroelectric and paraelectric phases occur). It was interesting to know whether the changes of Seebeck coefficient and of the investigated quantities would take place. 


\section{Experiment}

In order to determine the mechanisms of transport, the attempt to investigate the Seebeck effect was undertaken. The applied method of measuring the Seebeck coefficient has been described in [6]. The experiment was made using an automatic measuring device, which gives linear changes of the temperature gradient in the sample, while the average temperature of the sample remains constant at measuring the thermoelectric power. The device allows for a simultaneous measurement of the Seebeck coefficient. The temperature difference between two opposite surfaces of the sample was changed from $+6 \mathrm{~K}$ to $-6 \mathrm{~K}$ with the rate of $1 \mathrm{~K} / \mathrm{min}$. During the measurements the average temperature stabilized within the uncertainty of $\pm 0.5 \mathrm{~K}$. The sample used in our measurements had the shape of a disk (the diameter $d$ of which was equal to $0.00377 \mathrm{~m}$ and the surface $\mathrm{S}$ was equal to $0.00006 \mathrm{~m}^{2}$ ) with the deposited platinic electrodes. The platinum electrodes were placed on the sample by means of the vacuum evaporation techniques.

\section{Experimental results and discussion}

The type of electrical conduction was determined based on of the sign of the thermoelectric power of the sample-electrode colder junction. In SbSJ-modified, the $n$ type was observed.

The investigation of Seebeck effect consists in measuring the thermoelectric power $E_{\alpha}$ at a fixed gradient of temperature $\Delta T$ in the sample. When changing the magnitude and direction of the temperature gradient, the dependence $E_{\alpha}(\Delta t)$ is determined at a constant average temperature of the system (figures 1,2).

Figure 1 shows the dependence of the thermoelectric power on the temperature gradient. We can see that this dependence is linear and for different average temperatures the parameters $E_{0}$ are different. The dependence $E_{\alpha}=E_{\alpha}(\Delta T)$ can be expressed by the equation: $E_{\alpha}=E_{0}+a \Delta T$, where $\Delta T=T_{2}-T_{1}, E_{0}$ - the value the thermoelectric power for $\Delta T=0, T_{1}, T_{2}$ - the temperatures of the surface of the sample with electrodes.

The examples of temperature changes of $E_{0}$ observed in SbSJ:0.1\%Cl-crystals are shown in figure 2. The character of temperature dependence of this quantity is the evidence of its connection with the value and with the sign of the effective polarization (of spontaneous polarization and space charge). The value $E_{0}$ depends on the history of the sample and particularly on the previous acting of an electric field. It does not effect the value of the coefficient $\alpha$.

Using the above equation the Seebeck coefficients for different average temperatures are shown in figure 3. The course of the temperature dependence of Seebeck coefficient (figure 3) and the fact, that it changes its sign with the change of temperature indicate the significant contribution of both kinds of charge carriers (i.e. electrons and holes) to the charge transport. The observed dependence can result from the change of carriers number with the temperature change and with the location of the acceptor and donor levels relative to the valence and conduction bands. 


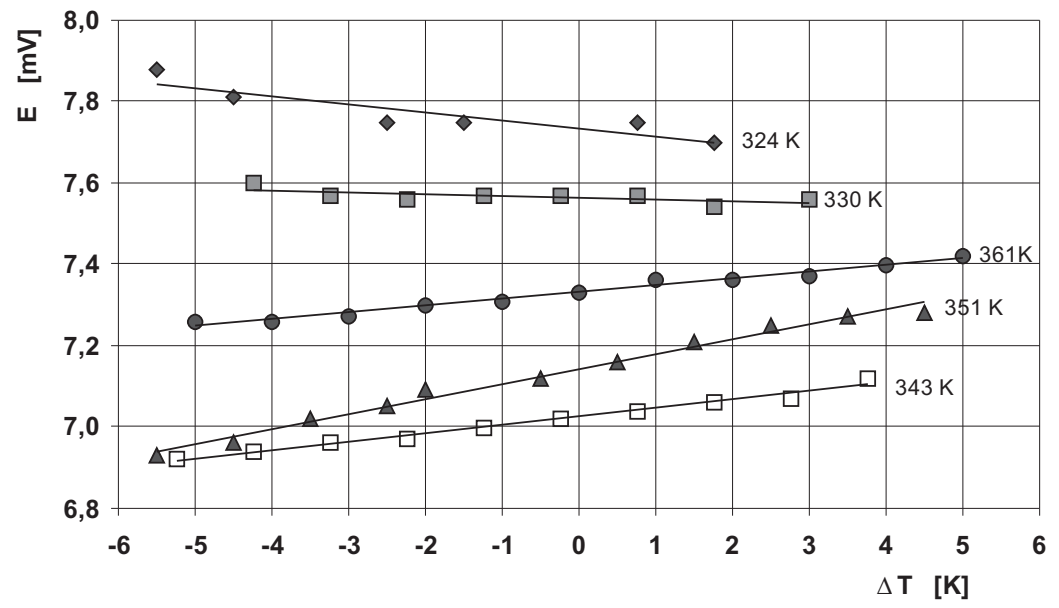

Figure 1. The dependence of the thermoelectric power versus temperature gradient.

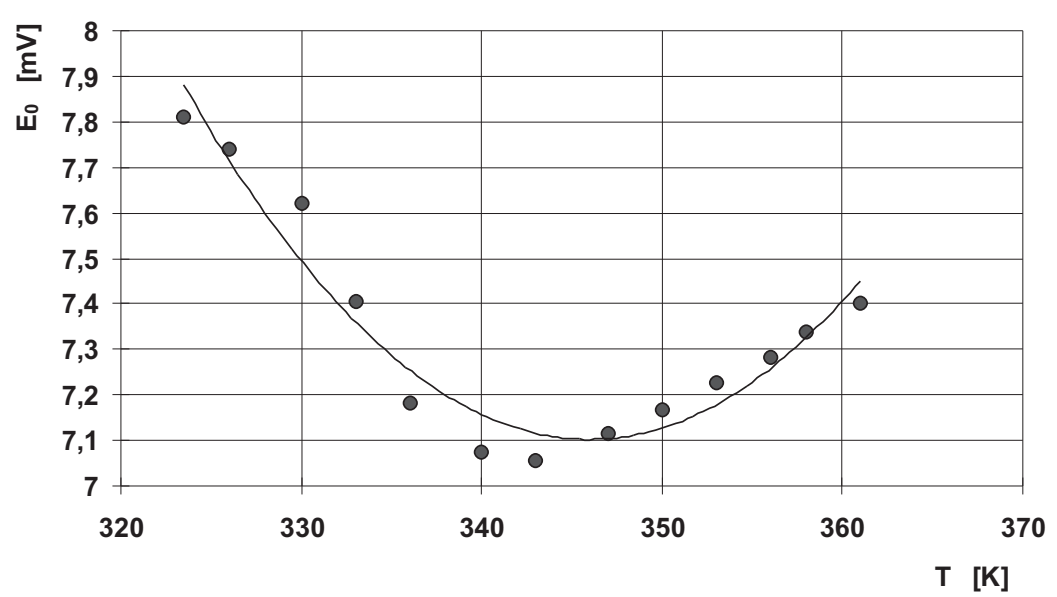

Figure 2. Temperature dependence of the thermoelectric power.

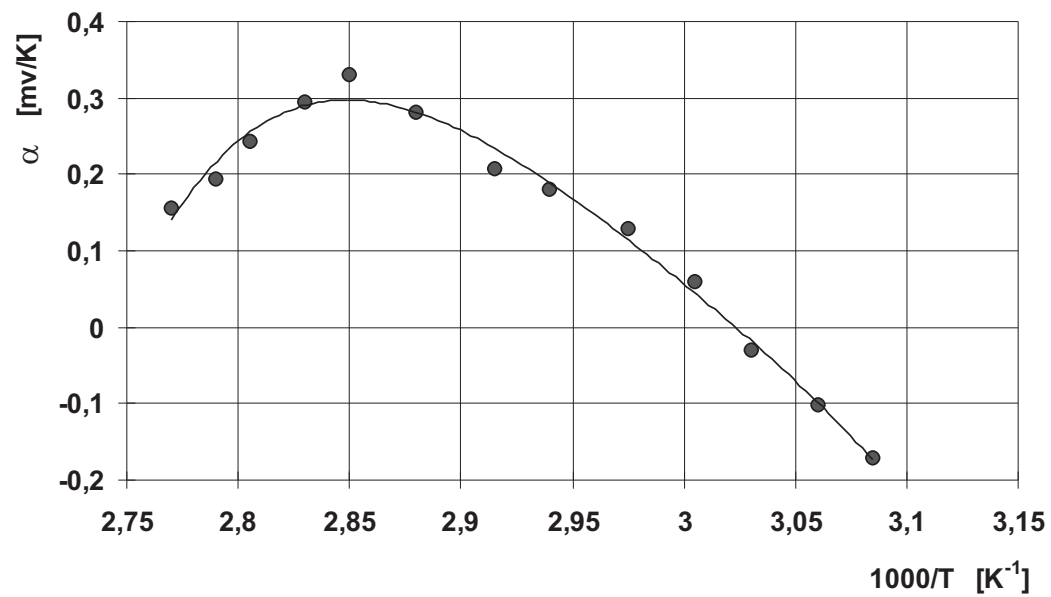

Figure 3. Temperature dependence of Seebeck coefficient. 


\section{References}

1. Steigmeier E.F., Auderset H., Haberke G. The central peak in SbSJ. // Phys. Stat. Sol. (b), 1975, vol. 70, p. 705-716.

2. Grigas J. Microwave Dielectric Spectroscopy of Ferroelectrics and Related Materials. Gordon and Breach Publishers, 1996.

3. Fridkin V.M. Photo-ferroelectrics. Berlin, Heidelberg, New-York, Springer Verlag, 1979.

4. Gierzanicz E.I., Fridkin V.M. Segnetoelektriki Tipa $\mathrm{A}^{V} \mathrm{~B}^{V I} \mathrm{C}^{V I I}$. Moskwa, Nauka, 1962 (in Russian).

5. Kudzin A.Yu., Suhynski A.N. Wlijanie oswieszczenia na formirowanie pietli dielektriczeskogo gisterezisa monokristalow SbSJ. // Solid State Physics, 1969, vol. 11, No. 6, p. $1389-1391$.

6. Kuś C, Śmiga W., Suchanicz J. Temperature changes of the Seebeck coefficient for nonstoichiometric $\mathrm{NaNbO}_{3}$. // Acta Universitatis Wratislaviensis, 1988, vol. 1084, p. 185191.

\section{Температурні зміни коефіцієнта Зеебека у модифікованому SbSJ}

\section{Б.Гарбаж}

Інститут фізики та обчислювальної техніки, Педагогічний університет,

Польща, 30-084 Краків, вул. Подхоронжих, 1

Отримано 1 вересня 1998 р., в остаточному вигляді 30 жовтня 1999 р.

В роботі наведено результати вимірювань коефіцієнта Зеебека для кристалу SbSJ:0.1\% Cl голкоподібної форми в діапазоні температур від $190 \mathrm{~K}$ до 370 К. Отримані результати дають можливість визначити тип і механізм електричної провідності в цьому кристалі.

Ключові слова: SbSJ, коефіцієнт Зеебека

PACS: 72.20.-i, 77.84.-s, 72.80.-r 